\title{
"Responding to Challenges: the Training and Educating of the Information Professional for the Next Millennium"
}

\author{
M. Burke \\ Senior Lecturer, Manchester Metropolitan University, UK
}

\author{
S. Millar \\ EduLib Developent Officer, The University of Abertay Dundee, UK
}

\section{Introduction}

'... in most fields the issue of the professional competence and qualification of individuals is viewed as an integral part of the quality assurance of organisations and the services that they provide.'

This view has long been embraced within the librarianship profession. Librarians and information professionals have a strong culture of responding to new opportunities in professional development to ensure that their skills meet the continually changing environments in which they work. This is illustrated by initiatives such as the Library Associations programme of Continuing Professional Development (CPD), Masters programmes for librarians entering management positions, increased availability of qualifications and training for paraprofessional staff and the adoption of the government instituted system of National Vocational Qualifications (NVQs) and Scottish Vocational Qualifications (SNVQs).

Two further initiatives have been undertaken as a response to concern about the pace of change and the importance of sustaining an adequately skilled professional workforce. Firstly, the Library and Information Studies Training and Education Network (LISTEN), is working with employers, the profession and educational institutions to identify, CPD and post-qualification competencies required when staff have been in post for several or more years. Secondly, the Electronic Libraries Programme (eLib) which aims to accelerate the development and uptake of the 'electronic library' has recognised the need for CPD and has funded a number of training and awareness projects including EduLib.

This paper will examine the role, education and training of information professionals from two distinct points of view. First the paper will concentrate on initial undergraduate training which students receive at an established Department of Library and Information Studies - with particular regard to the training and education of business information in order to prepare students for the global business world. The second part of the paper will deal with an aspect of continuing professional development for which there is an increasing demand in academic libraries - teaching skills for librarians. The paper will focus on EduLib - a development project which aims to provide a nationally recognised and accredited network of trainers in academic libraries. 


\section{Section One:}

\section{Initial Training: Responding to the Challenge of the External Environment}

Section one contains an analysis and discussion of the way in which an established Department of Library and Information Studies has recently altered the mainstream training courses in response to the changing social, political, technological and economic environment. This section one focuses specifically on the changes in business information and will include an analysis of the changes which have taken place in the sociological, technical, economic and political environments; a discussion of the new emerging markets for information professionals and finally an examination of the training of undergraduates in business information as part of the BA(Hons) and BSc(Hons) Information and Library Management Courses.

An information manager can be defined as a person whose primary task it is to coordinate information inputs and information outputs in organisations. The training of information managers is thus vital to the success of the organisation. An organisation, however, also needs specific business information if it is to survive in the future. The link between the training of information managers and business information can be seen as the link which allows organisations to prosper, companies to succeed, and industries to develop. Accurate information can provide the first link in the chain of events which can help to make and sustain a thriving economy.

The information world has expanded dramatically over the last decade due mainly to developments in communication. Information technology developments have resulted in new methods of communications whilst the latest telecommunications systems have altered the speed of communications. Both of these major changes have affected the way in which information is handled, stored and exchanged across the world.

These changes have also taken place against a backdrop of ever-enlarging business markets; from local to national and international markets. These changes have resulted in, and to some extent have been encouraged by, a competitive spirit and the strive for survival and success in difficult times. However, the success of all organisations could be seen to be dependent upon one key ingredient, namely information. In order to flourish an organisation must have information which is accurate, timely, understandable and presented in an appropriate format. The ability to present information in such a way is one of the vital skills of a good quality information manager.

It has been stated that the information profession needs quality managers in order to take advantage of new challenges ahead. Yet what is it that makes a quality manager, indeed what is quality? The internationally accepted formal definition of quality is 'the totality of features and characteristics of a product or service that bear on its ability to satisfy stated or implied needs' ${ }^{2}$. Other writers have defined quality as 'fitness for use and purpose, ${ }^{3}$, or as 'conformance to requirements' ${ }^{4}$. Quality managers could thus be defined as those who aim to fulfil customer needs in all aspects of their work. 
There is a strong need today on the provision of high quality information services in all sectors including academic institutions; public libraries; special and business libraries. Many job advertisements, within all sectors of the library and information provision, state to prospective applicants that they offer 'quality services'. If employers are seeking to operate a quality service, they will also be recruiting quality managers to run that service. The training of these quality managers is therefore vital to the success of the service.

Flexibility is one of the keys to success and by giving students the opportunities to combine and mix and match modules this is one way of allowing students to start sculpting their own career from the start. The Department of Library and Information studies at Manchester Metropolitan University have initiated an undergraduate programme whereby students can choose to specialise in business information or information management, or a little of both thus preparing them for their future roles as information managers in the year 2001 and beyond.

\section{Strategic Analysis}

A strategic analysis was important in order to ensure a closeness of 'fit' between the environment, the industry, and the organisation .Strategic analysis can be defined as 'the match an organisation makes between its own resources and the threats or risks and opportunities created by the external environment in which it operates, ${ }^{5}$. These external changes can be categorised under the following headings:-

\section{Sociological Changes}

-Expansion of job market to European Countries-

-Renewed interest in studying foreign languages-

-Demographic changes - ageing population-

-Increase in the amount of available leisure time-

\section{Technological Changes}

-High technological development-

-Increase in the speed of communication-

-IT developments which have led to changes in traditional working methods-

\section{Economic Changes}

-Increasing competitiveness-

-The creation of Business Links to encourage small and medium size

businesses to develop successfully

-Reduced government funding for libraries resulting in increased pressure

to charge for information-

-Removal of trade barriers to facilitate import and export

\section{Political Changes}

-Emergence of East European Countries

-Business now has unlimited access to world-wide labour at competitive costs

-Growth of multinational companies- 


\section{Information Implications}

All the factors identified above have implications for today's information professional in the following ways:

\section{Sociological Implications}

Librarians and information managers of all kinds are now able to consider work in a variety of European countries, due to the expanding job market. Students have also expressed interest in combining their degree with the study of languages.

There is a renewed interest in leisure activities and especially in reading. A recent survey found that $48 \%$ of all adults (15yrs+) were currently reading a book for pleasure at the time of interview. ${ }^{6}$ Librarians thus need to be aware of changing consumer tastes and the demand placed on libraries by all sections of the community.

\section{Technological Implications}

Due to the increased use and availability of fax machines, electronic mail systems, computer networks and the Internet, businesses are now able to work at local, national and international levels. Thus the huge amount of information which is available needs to be organised in a comprehensive way to be of any real value. The information technology skills of information managers are currently utilised and increasingly recognised by the job market as skills which hold the key to the comprehensive management of information.

\section{Economic Implications}

Business information units are now partners in Business Link centres. In order for companies to compete at all levels there is a need to provide quality information. There is therefore a need to train graduates to have both a sense of business acumen and the necessary skills in information management.

\section{Political Implications}

Business information is needed by and about the developing Eastern European and Pacific Rim countries in order to set up new structured industries - accurate business information is essential for the successful implementation and growth of a market economy.

\section{Training for Business Information}

During 1994 the BA (Hons) Information and Library Management course underwent a major restructuring. Business, always a popular option on the previous course had become, in marketing terms, a "rising star". This was due to the environmental changes combined with a number of factors which together formed the catalyst for change:- 


\section{The Catalyst}

1) Increasing numbers of students showing interest in this area

2) Evidence that our graduates were increasingly employed in business and specialist type areas where information management skills were required.

3) An awareness that employers required not only business information skills but also needed this knowledge to be combined with an understanding and appreciation of the business world.

4) The extension of the job market into Europe

\section{The Response}

All these facts became the catalyst for change. We responded by changing the product i.e. the course in such as way as to allow for choice, and yet still remain flexible enough to cater to all needs. The result is a course which builds up layers of knowledge and allows students to choose named pathways throughout the course. There are three named pathways: Business, Young People, and Information Management. The rest of this paper will focus on a discussion of the training in the Business pathway.

\section{The Result}

In the first year of the degree all students undertake a compulsory course called an "Introduction to Business Information". This ensures that even those students who do not wish to choose to specialise in business still have a thorough grounding in the sources and principles of business information.

In the second year of the degree there are a range of business courses offered, namely:

Business Regulations and Control

Business Marketing

Business Strategies

Business Finance

Business: Global Perspectives

Each of these units are designed to complement each other and yet can be studied as an isolated unit. However, the student who opts to study the integrated package will be poised to become an invaluable asset to an organisations information needs. In addition to these changes, students now also have the option to study a language during the degree course. 


\section{The Product in detail}

Product 1: Business Regulations and Control

The student gains knowledge and understanding of a variety of regulations which affect businesses, for example:-

Standards,

Patents,

Trade Marks and Brands

Acts and Statutory Instruments

Consumer Protection.

Trading Standards

Product 2: Business Marketing

This module examines the marketing principles including product life cycles and product strategies. This is combined with a study of the importance of market research and an examination of how marketing strategies can be utilised in a competitive environment.

Product 3: Business Finance

This module trains the student to read and analyse financial information and allows the student to have an overall view of the financial world together with an appreciation of internal finance in an organisation.

Product 4: Business Strategy

This unit aims to give students an appreciation of the central role which information plays in creating and sustaining strategy. This is a very intensive module and covers areas such as strategic analysis, internal and external appraisal and strategic change.

Product 5: Business: Global Perspectives

This is the final business unit of the course and as such it acts as a way forward for the future growth and development of business information. Aspects such as European and international sources of business information and the globalisation of industries, such as the car industry are covered in this module. The students also study the rise of the Pacific Basin countries; the possibility of a third strong economic bloc; developing trade information and the importance of cultural differences when conducting business.

\section{Discussion}

The aim of the training is to produce good quality information managers who have a thorough grasp understanding and knowledge of business and the business world. However the successful training and production of high quality business information managers is of course one that is affected by a range of issues such as the personal 
qualities and characteristics of individuals; relevant work and background experience; levels and areas of responsibility and the size and type of the business organisation which is recruiting for an information manager. Nevertheless, training quality information managers is considered to be essential to the continuing development of the information profession.

The business information teaching model adopted by the Department has been refined in that staff have endeavoured to enhance the quality that exists in students. It is hoped that this approach may be of interest to information professionals of other countries whose business strategies may bee under consideration. Finally it is hoped that the production of quality business information managers will impact on a wider world leading to internationally exchangeable skills and greater professional mobility.

\section{Section Two:}

\section{Continuing Training: Responding to the Challenge of the Networked Environment}

Section two contains an explanation and discussion of a new library project called 'EduLib'. This project is specifically aimed at practising librarians and information workers in academic libraries.

EduLib addresses the training needs of academic librarians involved in teaching and learning. Academic librarians have traditionally had a role in the education of end users of information. The extent of this educational role has varied (not exclusively) from short 'one to one' training sessions resulting from enquiries or requests by individuals for assistance to find information; induction training of new students; ad hoc class contact arranged outside the curriculum and formal integration of information skills within courses or modules. Changes taking place within the education system and the information and technological environment are influencing an increasing demand for the teaching and learning role of librarians to be more firmly embedded within the educational process.

Recent trends within higher education such as rapid expansion of student numbers within a relatively short time span; fewer class contact hours and emphasis on problem based learning and student centred study have placed many pressures on libraries. These pressures are coupled with the challenges and opportunities of the rapidly developing world of networked information. The 'virtual library', the 'virtual research desk' and the 'virtual office' may have a single point of access to the world of information i.e. a single workstation, but they bring with them a myriad of training needs which would surpass those required to make effective use of the most complex physical library system. Networked information pervades the education sector, the business sector and increasingly is also available in the home. Information skills developed during a programme of undergraduate or postgraduate study are now more than ever before 'transferable' into the world of research, the world of business and now also the world of leisure. 
Library end-users require education and training if they are to make the most effective and productive use of networked and electronic information services. This training goes beyond technical computer literacy which is also required. Users must be able to analyse and define their information need; be able to identify, and select the best source to use; search effectively; evaluate the information retrieved and modify the search if necessary; and eventually be able to obtain and use materials identified in their search. If this training is provided only by information technology specialists there is a danger that the technical computing skills will be emphasised at the expense of an in-depth understanding of the information content including the structure and skills of information retrieval. It is essential that librarians are involved in this education process and work in partnership with IT and academic colleagues.

Involvement in the teaching and learning process is not new to some academic librarians and indeed it can be argued that the generic information skills to be taught are not significantly different from those required to use print based materials. What is different is the medium. The electronic medium is continually in a state of change and librarians must keep pace in developing their own skills if they are to be able to impart learning for the 'electronic library' to others, both students and academic staff and also in staff development for other library and support workers. One of the significant differences of the electronic medium is that it is popular. Library users are queuing for CD ROM and networked workstations, to level a which would never have been considered for print based abstracting and indexing services. Some academic and research staff already find electronic communication, publishing and information retrieval a way of life but many are still not using the technology. There are many reasons for the latter situation including, limited access to equipment, cultural reluctance to change, but for some there is a feeling of insecurity and desperate need for training.

Librarians must extend their traditional roles as information specialists to become key agents in the provision of training in the use of networked information. To equip them for this role librarians need to develop their own professional skills in the areas of information technology but more importantly their own training in educational methods and learning strategies.

The Joint Funding Councils' Library Review Group: Report ${ }^{7}$ which was published in 1993 and commonly known as the Follet Report made many recommendations related to the ways in which the use of information technology in the electronic library can help to alleviate some of the problems of university libraries today. It stressed the increasingly important role which libraries must play in the turning of the use of networked information resources into an everyday part of teaching, learning and research. The Report (parag. 306) specifically states that librarians

'need to be able to train their users to cope with the vast amount of networked information that is now available.'

In response to the recommendations of the Follet Report, the Joint Information Systems Committee (JISC) established the Electronic Libraries Programme (eLib). The programme has a budget of $£ 15$ million over 3 years, and its objectives include the use of information technology to improve delivery of information through 
increased use of electronic library services. To meet these objectives the Follet Report ${ }^{7}$ (parag. 305) recognised the need for training and staff development:

'...some librarians are daunted by such a challenge, and enthusiasms can be dampened where relevant training is not provided. The development of new skills is particularly important where information is provided through electronic services accessible over networks'

eLib consequently includes an important group of projects in the area of Training and Awareness including EduLib. EduLib focuses on the skills of teaching and learning that librarians require to train library end-users.

EduLib has close links with a number of other projects which are complementary to developing a whole package of staff development required to support users of networked information. Netskills which is based at the University of Newcastle provides workshops to introduce techniques of accessing and using the Internet. Ariadne which is a joint project between the University of Abertay Dundee and UKOLN at the University of Bath publishes The Internet Magazine for Librarians and Information Specialists. The magazine provides awareness of new developments in networked information and aims to keep librarians up to date in this critical area. DeLiberations, the electronic magazine emanating from the London Guildhall University provides a forum for awareness and discussion on teaching and learning issues.

These projects are mentioned to emphasise that EduLib does not intend to train librarians to access the Internet. Additional knowledge about networked systems is essential but that will be provided in other ways including Netskills and Ariadne. EduLib is concerned with how librarians use information technology within the learning process, either to impart learning on how to use networked information or to develop learning materials which utilise computer systems. It is stressed that an:

'educational perspective upon technology in education is a critical factor in whether it actually enhances learning and offers new approaches or whether it is simply produced and applied without sound pedagogical underpinning and the critical scrutiny of those who might use it. ${ }^{\mathbf{8}}$

DeLiberations provides a vehicle for evaluation and debate on how information technology is incorporated into the learning process. It aims to involve and support library staff, academic staff, computing staff, and educational developers so that it brings together a range of perspectives of those involved right across the learning environment. Understanding and dialogue with this diverse group of people and interests is essential to EduLib in developing working relationships and partnerships with those involved in the academic process.

\section{Aims and Objectives of EduLib}

EduLib is a development project with the remit to encourage the involvement of institutions in educational development of librarians and to explore ways in which this can be supported. ${ }^{8}$ 
In order to carry out its mandate and ensure that the appropriate mix of experience and expertise may be focused upon achieving the project's aims EduLib is based upon an association between:

- The University of Hull, which has an established educational and staff development record and also has programmes in place to equip university staff with teaching skills.

- The University of Abertay Dundee, which has responded proactively to the need to train and support users of networked information by developing the Library and information Skills Programme in partnership with modular teaching.

- The Staff and Educational Development Association, which is taking the initiative in offering nationally accredited teaching qualifications for higher education teaching staff.

The specific aims of the project are summarised as follows: ${ }^{9}$

a) to specify and to provide to librarians working in higher education institutions the skills and capabilities which will enable them to execute their training and awareness-raising roles, and to communicate effectively with client groups in ways which will ensure that these end-users, staff and students alike, can adopt and incorporate new information resources and the skills to utilise them within their own teaching, learning and research;

b) to foster, within the higher education library community, a professional culture which recognises that, with the advent of the digital library, professional roles will change and that librarians will need to acquire training in teaching methods and staff development skills, and that in the longer term librarians will need to develop the capacity to take a measure of responsibility for their own professional development in order to fulfil these new roles;

c) to produce a training programme and associated learning materials which will be disseminated and continue to be in the public domain after the completion of the project.

To achieve these aims EduLib will first work with a Development Team of practising librarians to pilot a programme in educational methods. In the piloting stage the programme is closely based on a generic higher education teaching qualification which is available to academic teaching staff and is designed to meet the objectives of the Staff and Educational Development Association (SEDA) Teacher Accreditation Scheme. There are three key objectives for the Development team:

a) To develop their own educational skills and demonstrate their competence in teaching and learning by completing the programme and achieving a Higher Education Teaching Diploma (at this stage offered by the University of Hull), to enable them to further develop those skills in others.

b) To work with the workshop leaders of the pilot programme and the Core Team which directs and manages the project, to adapt and modify the workshop content 
and materials to meet the needs of librarians.

c) To disseminate the programme once it has been revised and tailored for librarians to a wider network of professional colleagues organised on the basis of regional consortia.

The EduLib Development Team members do not only represent the geographical areas on which the proposed Consortia are based but also the cultural diversity of Higher Education System in the UK. The members were selected as representatives based on their commitment to and experience of training either in a staff development role or teaching information skills and also on their familiarity with networked information resources.

\section{Qualifications and Accreditation}

The first phase of the EduLib project was identification of needs and consensus building. This phase lasted four months and involved surveying librarians by use of a Training Needs Analysis ${ }^{10}$ to develop an understanding of their educational needs. Opinions were also gathered at a series of 5 awareness and discussion days which were held throughout the UK during the consensus building period.

The views which were expressed in the formal questionnaire and in the discussions were strongly in favour of the need for an initiative like EduLib. Most librarians early on in their careers did not expect to become involved in formal teaching so for many there is a feeling of 'in at the deep end' without any initial training or support. It was also reported that while many librarians welcome working with their academic colleagues and are actively seeking to incorporate information skills programmes into mainstream courses, some librarians had encountered resistance to this integration. The explanation most frequently given for this resistance, related to a perceived lack of status for the librarian in a teaching role, amongst academic staff and higher education management.

It was generally agreed that library staff should have access to a qualification in teaching and learning to extend their skills and professional competence and also to be able to demonstrate this to others through a qualification and accreditation.

The system of subject based Teaching Quality Assessments (TQAs) in UK higher education includes the role of support services. Experience at the University of Abertay Dundee has shown that the Assessors are very interested in the integration of the Library and Information Skills Programme within course modules. SCONUL were recently invited by the Higher and Education Funding Council (HEFCE) to submit an aide-memóire for the guidance of Assessors when they examine library and computer services as part of the TQA process. In the proposed document ${ }^{11}$ it is recommended that the Assessors ask:

'what are the arrangements to ensure that students and staff are able to make the best possible use of the range of available library and computing services?' 
This recommendation fits closely with the observation of The Follet Report ${ }^{7}$ (parag.121) that:

'Subject librarians, enquiry desk staff, and others need to be able to play an active role in supporting students in their teaching and learning, including providing guidance in how to use the facilities provided by a library, through to subject-specific advice on project work and source materials.'

It can be expected that libraries will receive closer scrutiny in future into the ways in which they support the user in their teaching and learning.

Higher Education academic staff themselves are sometimes criticised for the absence of professional accreditation of their teaching. This situation is changing however and professional accreditation is now is very much at the centre of discussion within the sector. Quality assurance until now has been concentrated at the departmental and institutional level but proposals to link funding to good teaching are currently under consideration. $^{12}$

Various initiatives already address quality and innovation in teaching. Many institutions have developed educational development centres to stimulate and support innovation in learning, teaching and assessment and to promote educational skills for teaching staff. Institutional programmes of educational staff development are often developed, and new lecturers in particular are encouraged to participate. At a national level, organisations including SEDA and the Universities and Colleges Staff Development Association (UCoSDA) are working towards models and standards for the accreditation of higher education teaching qualifications. Such qualifications are now offered by a number of institutions such as the University of Hull Higher Education Teaching Diploma which is accredited by SEDA and upon which the EduLib pilot programme is being developed.

If higher education teaching qualifications gradually become an accepted standard within universities then it can be expected that librarians should be similarly qualified to be involved in teaching. Indeed the Association of University Teachers (AUT) have supported the view that academic related staff including librarians: ${ }^{1}$

'in so far as they do teach should have full access to development, training and accreditation opportunities'

The AUT is supportive of more professional training for it's members, taking the view that: ${ }^{1}$

'Either the profession itself grapples with these complex and difficult questions of qualifications and standards, or some system, appropriate or otherwise, will be imposed from the outside.'

In part, the AUT view is similar to the philosophy of EduLib that: ${ }^{13}$

'... the library community has some investment in and 'ownership' of the programme materials and responsibility with their institutions for 
developing models of staff development such as EduLib. But in the longer term it has to go deeper than this. Projects like EduLib have a limited life. The need for the sort of input which will be provided by EduLib will, however, continue into the future. It will be for the HE library community to ensure that it takes over the responsibility for its own appropriate professional training in the years ahead. To this end it is important that the project helps develop a professional culture within which key librarians take over the responsibility for their own professional training in teaching skills.'

\section{A separate qualification for librarians?}

It can be argued that librarians may receive educational staff development via generic programmes which already exist and indeed some librarians do take up such opportunities. Why then is there a need for EduLib?

Firstly it may be argued that access to accredited programmes throughout the country is still patchy and is not available in all institutions or even in all regions. EduLib aims to disseminate the programme on a regional consortia basis to allow maximum access for librarians.

More significantly however EduLib recognises that librarians interact with students in circumstances which are different from their academic colleagues. Librarians tend to encounter students in short one off sessions which may or not be part of a module of a course. They may only see a group of students once or twice during their course. There is little opportunity to develop long term relationships with learners and it is difficult to establish how much experience, skills and knowledge that students already have and what their specific learning needs are. Librarians are seldom involved in student assessment and it is difficult to obtain meaningful feedback on the students learning and the librarians performance as a 'teacher'.

It is essential for EduLib to collaborate with librarians to identify the different circumstances in which they teach and offer appropriate training advice tailored to their needs. The educationalists who have been involved in delivering the initial programme of workshops for the Development Team have mostly agreed that they themselves have learnt much about unusual learning situations from the team and agree that the circumstances in which librarians teach are somewhat challenging. In particular they have commented on situations which are difficult due to an absence of student assessment. In the current economic climate however with pressure on resources and staff time it is unlikely that librarians will become involved in assessment to a very great extent and they must find other ways to improve the quality of the learning process that they are involved with.

\section{Progress of EduLib}

EduLib is organised into four phases. These are not completely discrete phases and developments in one phase influence what happens in the next.

Phase One - Identification of needs and consensus building (September - December 1995) 
The training needs analysis (TNA) and awareness days for librarians which formed the basis of this phase are discussed earlier in this paper. The findings of the TNA have already been analysed and distributed. ${ }^{10}$

\section{Phase Two - Development and piloting of draft materials}

(January - December 1996)

The Development Team have completed the initial pilot programme of workshops and are currently involved in preparation of their assessment in order to obtain higher education teaching qualification which is validated by the University of Hull and accredited by SEDA. Throughout the workshop programme the Development Team have evaluated the workshops with particular regard to their suitability to the circumstances in which librarians work. This evaluation will form a basis for the revision and planning of the materials and programme in the next phase of the project. During phase two the team will also explore the feasibility of establishing similar qualifications in other institutions alongside, or independent of, existing educational provision for higher education teaching staff.

Phase Three - Production and delivery of finished versions of the training programme

(January 1996 - September 1997)

The programme materials will be revised and published. It is anticipated that they will be available in both hard copy and electronically. EduLib is currently exploring the possibility of co-operation with DeLiberations to add value to the materials and extend their audience and accessibility.

Once the materials are published the training programme will be launched on a national scale. The Core Team and the Development Team will use the training materials to offer programmes on a regional basis and will also advise on the implementation of the materials where they become embedded in institutional programmes.

\section{Phase 4 - Continuation and backup}

It is critical that the programme continues to exist after the funded lifetime of the project. It is anticipated that this will be achieved through embedding the approach into higher education institutions during the first three years. It will then continue to be disseminate through individual institutions by means of the staff development activities of those already trained, and, it is hoped, as part of a coherent institutional policy. The University of Hull has guaranteed to ensure that the materials are kept up to date for a period of three years after the completion of the project.

EduLib is a developmental project and it is difficult to predict the eventual outcomes and successes. EduLib is therefore working in close association with the evaluation programme IMPEL2 (Impact of People in Electronic Libraries) which is also funded under eLib. IMPEL2 uses methodology developed and tested under an earlier project (IMPEL1) to monitor organisational and cultural change. One of the four IMPEL2 projects specifically focuses on EduLib and should allow an in-depth analysis of the impact of EduLib on the higher education library community. 


\section{Conclusion}

This paper has examined two responses to the need to provide flexible education and training for information professionals.

First the paper has described the strategic analysis which was carried out in the early stages of the design of an information degree course and explored ideas on how to train quality business information managers. In designing a course for the information world, account should be taken of the problems and difficulties of functioning as a 'quality' manager within inevitable constraints such as diminishing resources and inadequate staffing levels. The training of managers for the information world can be seen as one of the keys to the success of organisations. However, whatever training and guidance is given to produce quality business information managers, it is only when students are employed that the success of any training can properly determined.

Initial training however must be kept up to date throughout the working life of the information professional. It is therefore essential that training is ongoing and promotes adaptability to new situations. The second part of the paper has therefore been devoted to EduLib, an academic library training initiative which responds to the expanding role of librarians as educators.

EduLib provides an example of an innovative approach to providing Higher Education librarians with the educational skills which are required if they are to make effective use of networked information. However, many more demands are likely to be placed upon professionals working in the constantly changing arena of HE, but there will not always be a well funded project available to respond such challenges. What is different about EduLib is the underlying model which aims to foster within the HE community, a professional culture and collective capacity to take a measure of responsibility for their own professional development and to fulfil these, and other, new roles. Information professionals are already well organised and structured to provide CPD and have demonstrated in many ways that they have taken responsibility for their own development. It is anticipated that EduLib might assess and accelerate not only the professional capacity to develop for change, but also improve institutional readiness and flexibility to enable change.

The two training developments discussed here aim to provide conceptual frameworks, knowledge of best practice, tools and techniques. All training is reviewed on a regular basis to take account of changing business practices, professional issues and emerging trends in order to produce professionals which are educationally and academically acceptable in world where information has become a vital resource. 


\section{References}

1. Association of University Teachers, Professional accreditation of university teaching.. AUT Bulletin (Supplement). January 1996.

2. BSI. BS EN ISO 8402: Quality management and quality assurance. Vocabulary. London, BSI, 1985, p1.

3. Juran, J., Cited in: Lascelles D. and Dale B., The road to quality. Bedford: IFS, $1993, \mathrm{p} 2$.

4. Crosby, P., Cited in: Lascelles D. and Dale B., The road to quality. Bedford: IFS, 1993 p.3.

5. Bowman, C. \& Asch, D., Strategic management. London, Macmillan, 1987, p4.

6. Book Marketing Ltd., Consumer survey on adult book buying and reading habits in Britain. London: Book Marketing, 1995.

7. Joint Funding Councils' Libraries Review Group. Report. Bristol: Higher Education Funding Council, 1993. The text of the Report is available at URL http://ukoln.bath.ac.uk/follett/follett_report.html

8. Core, J. \& McNamara, D., Educational development for higher education library staff: a paper presented to the LIBER Silver Jubilee Annual Conference, University of Malta, 24th May 1996. [In publication for LIBER Quarterly].

9. McNamara, D. \& Core, J., Accredited training in teaching for higher education librarians: problems of disseminating expertise: paper presented to the 1st International Conference of the SEDA Learning Technologies Group, University of Derby, 25th June 1996.

10.McNamara, D. et al., Higher education librarians as educators: a training needs analysis. [1996]. Summary available at: URL:

http://www.hull.ac.uk/Hull/CTLS_Web/edulib/edulib.html

11.Sykes, J., Letter to Chief Librarians on behalf of the SCONUL Working Group on Quality Assurance detailing proposals for Aide-Mémoire for Assessors when evaluating library and computing services. 1 May 1996.

12.MacLoed, D., Cult of the amateur lingers on. Guardian education. Tuesday 11 June 1996.

13.Core, J.\& McNamara, D., EduLib: a model of staff development for higher education librarians as teaching and learning partners in the electronic library: paper presented at the Computers in Libraries International Conference. London, 21 February 1996.

Further information about the organisations mentioned in this report may be obtained on the World Wide Web at the following addresses:

\section{Ariadne}

http://ukoln.bath.ac.uk/ariadne 
Association of University Teachers

http://www.aut.org.uk/main.html

\section{DeLiberations}

http;//www.lgu.ac.uk/lem/hom.html

\section{EduLib}

http://www.hull.ac.uk/Hull/CTLS_Web/edulib/edulib.html

eLib - Electronic Libraries Programme

http://ukoln.bath.ac.uk/elib/projects.html

IMPEL2 - Impact of People in Libraries

http://www.unn.ac.uk/ liw5/IMPEL2.html

JISC - Joint Information Systems Committee

http://www.niss.ac.uk/education/jasper/intro.html

\section{Manchester Metropolitan University}

http://ehlana.mmu.ac.uk/

\section{Netskills}

http://www.netskills.ac.uk

SEDA - The Staff and Educational Developent Association http://info.ex.ac.uk/public_html/SEDA.html

UCoSDA - The Universities and Colleges Staff Development Association http://www.shef.ac.uk/uni/services/ucosda/

\section{University of Abertay Dundee}

http://www.tay.ac.uk

\section{University of Hull}

http://www.hull.ac.uk/Hull/CTLS_Web 